\title{
Effects of endothelin-1 on airway and parenchymal mechanics in guinea-pigs
}

\author{
Á. Adamicza*, F. Peták ${ }^{+}$, T. Asztalos ${ }^{+}$, Z. Hantos $^{+}$
}

\begin{abstract}
Effects of endothelin-1 on airway and parenchymal mechanics in guinea-pigs. Á. Adamicza, F. Peták, T. Asztalos, Z. Hantos. (C)ERS Journals Ltd 1999.

ABSTRACT: The contributions of the airways and the parenchyma to the overall lung mechanical response to endothelin-1 (ET-1) have not been systematically studied. In this investigation, the ET-1 induced changes on lung mechanics in guinea-pigs were separated into airway and parenchymal components.

Pulmonary impedance (ZL) data were collected between 0.5 and $21 \mathrm{~Hz}$ in six anaesthetized, paralysed, open-chest animals by introducing small-amplitude pseudorandom oscillations into the trachea through a wave tube. $Z \mathrm{~L}$ was calculated before and following intravenous boluses of ET-1, with doses doubled from 0.125-2 $\mu \mathrm{g} \cdot \mathrm{kg}$ of body weight ${ }^{-1}$. A model containing an airway resistance (Raw) and inertance (Iaw) and tissue damping $(G)$ and elastance $(H)$ was fitted to the $Z L$ spectra in each condition. Parenchymal hysteresis $(\eta)$ was calculated as $G / H$.

After each dose, ET-1 induced significant increases in $R$ aw (at peak response mean \pm SEM: $424 \pm 129 \%), G(400 \pm 80 \%), H(95 \pm 22 \%)$ and $\eta(156 \pm 33 \%)$, whereas $I a w$ decreased following the two highest doses $(-291 \pm 77 \%)$.

These data suggest that the parenchymal constriction was accompanied by inhomogeneous constriction of the peripheral airways.

Eur Respir J 1999; 13: 767-774.
\end{abstract}

\begin{abstract}
*Institute of Experimental Surgery and ${ }^{+}$Dept of Medical Informatics and Engineering, Albert Szent Györgyi Medical University, Szeged, Hungary.

Correspondence: Z. Hantos, Dept of Medical Informatics and Engineering, Albert Szent-Györgyi Medical University, H-6701 Szeged, P.O. Box 2009, Hungary. Fax: 3662454566
\end{abstract}

Keywords: Airway resistance, bronchoconstriction, lung elastance, lung impedance, parenchymal resistance

Received: July 291998

Accepted after revision December 71998

This study was supported by Hungarian OTKA grants T016308, T016889 and T023089.
Endothelin-1 (ET-1) was originally described as a potent smooth muscle constrictor derived from vascular endothelial cells [1]. Numerous subsequent studies on the synthesis of ET-1 in nonvascular cell types, such as airway epithelial cells, type II pneumocytes and alveolar macrophages [24], have indicated the physiological and pathophysiological importance of this peptide in the lung. It is also known that ET-1 exerts a constrictor effect on both the vascular and the bronchial smooth muscles [5-11] However, the overall effect of ET-1 on lung mechanics has not been completely characterized.

Previous studies revealed dose-dependent increases in the peak pulmonary inflation pressure (PIP) [7, 9, 10], or elevations in the total lung resistance $(R \mathrm{~L})$ with a concurrent decrease in the dynamic lung compliance $(C$ dyn $)$ following the $i$.v. injection of ET-1 into guinea-pigs $[5,6,8$, 11]. The measurement of these global lung mechanical parameters, however, does not allow a separate estimation of the changes in the mechanical properties of the airways and parenchyma. Recent studies partitioning the lung responses to various constrictor agents into airway and parenchymal components established the importance of the elevated tissue resistance $(R \mathrm{ti})$ accompanying bronchoconstriction [12-20]. The only study on separation of the airway and parenchymal responses to ET-1 was reported by NAGASE et al. [16], who measured local alveolar pressures $(P A)$ through one or two alveolar capsules in guinea-pigs. It has been demonstrated, however, that PA exhibits a significant heterogeneity during constriction, which makes separations based on the measurement of PA highly accidental $[12,21]$. Further, recent studies involving a model- based evaluation of lung impedance $(Z \mathrm{~L})$ revealed that the parameters of a model of pulmonary mechanics estimated from low-frequency $Z \mathrm{~L}$ spectra characterize the airway and parenchymal mechanics accurately both in control conditions and during induced constrictions $[12,14,15,17,19$ 23]. The aim of the present study, therefore, was to apply a model-based evaluation of ZL data to investigate how ET-1 alters the separate mechanical properties of the airways and the parenchyma in guinea-pigs.

\section{Methods}

\section{Animal preparation}

Six Hartley guinea-pigs, weighing 470-560 g, were anaesthetized with pentobarbital sodium $(30 \mathrm{mg} \cdot \mathrm{kg}$ of body weight $^{-1}$, i.p.). The animals were placed in the supine position on a heating pad to maintain the body temperature at $\sim 37^{\circ} \mathrm{C}$. A catheter in the carotid artery was used to measure arterial blood pressure (BP) by a transducer (Statham P23Db; Statham Instruments, Hato Rey, Puerto Rico). A jugular vein was cannulated for drug administration. After tracheostomy, a plastic cannula $(\mathrm{l}=30 \mathrm{~mm}$, $\mathrm{ID}=2 \mathrm{~mm}$ ) was introduced into the distal end of the trachea. Paralysis was accomplished with pipecuronium bromide $\left(0.2 \mathrm{mg} \cdot \mathrm{kg}\right.$ of body weight $\left.{ }^{-1}\right)$ and the animal was ventilated by a Harvard small animal respirator (Harvard Apparatus, South Natick, MA, USA) with a tidal volume of $6 \mathrm{~mL} \cdot \mathrm{kg}$ of body weight ${ }^{-1}$ and respiratory frequency of 70 breaths $\cdot \mathrm{min}^{-1}$. After midline sternotomy, the ribs were 
widely retracted and a positive end-expiratory pressure (PEEP) of $2.5 \mathrm{hPa}$ was applied. Maintenance doses of anaesthetic $\left(10 \mathrm{mg} \cdot \mathrm{kg}\right.$ of body weight $\left.\mathrm{t}^{-1}\right)$ and paralytic $\left(0.05 \mathrm{mg} \cdot \mathrm{kg}\right.$ of body weight $\left.{ }^{-1}\right)$ were given as needed.

At the end of the experiments, the lungs were excised from each guinea-pig challenged with ET-1, and the ratio of the wet weight to the dry weight of the lungs (WW/DW) was calculated to estimate the amount of pulmonary oedema. The WW/DW values obtained in the main study population were compared with those calculated from another group of untreated normal guinea-pigs $(n=7)$.

\section{Study protocol}

The measurements of $Z \mathrm{~L}$ were made in the control conditions and following every i.v. bolus of ET-1 (Alexis Corp., Läufelfingen, Switzerland) by doubling the doses from $0.125-2 \mu \mathrm{g} \cdot \mathrm{kg}$ of body weight ${ }^{-1}$. Prior to each dose, 3-6 measurements were made to establish the baselines. ZL was recorded $0.5,1,2,4,6$ and 8 min after each ET-1 bolus. Before the control measurements, the lungs were hyperinflated by superimposing two inspirations to open the possible atelectatic areas.

\section{Measurements of $\mathrm{Z}_{L}$}

The wave-tube technique [24] was applied to determine the $Z \mathrm{~L}$ spectra, as described in detail previously [19]. Briefly, a loudspeaker-in-box system and the tracheal cannula were connected through a polyethylene wave tube $(\mathrm{l}=105 \mathrm{~cm}, \mathrm{ID}=2 \mathrm{~mm})$ during apnoeic periods. Lateral pressures were sensed at both ends of the wave tube with ICS transducers (33NA002D; ICSensors, Milpitas, CA, USA). The mechanical ventilation was interrupted at endexpiration and a forcing signal was introduced into the trachea. The computer-generated small-amplitude pseudorandom signal contained 23 noninteger multiple frequency components between 0.5 and $21 \mathrm{~Hz}$. The pressure signals were low-pass filtered ( $25 \mathrm{~Hz}$, 5th-order Butterworth) and digitized at a sampling rate of $128 \mathrm{~Hz}$ by an analogue-todigital board of an IBM-compatible computer. Fast Fourier transformation was used to calculate the pressure transfer function spectra from the 6-s recordings by using 4-s time windows and $97 \%$ overlapping. ZL was computed as the load impedance of the wave tube by using the transmission line theory $[24,25]$.

\section{Parameter estimation}

A model containing an airway and a constant-phase tissue compartment $[12,22]$ was fitted to the $Z \mathrm{~L}$ data by minimizing the squared sum of weighted differences between the measured and the modelled impedance data (F). The airways were characterized by a frequency-independent airway resistance (Raw) and inertance (Iaw), while the tissue compartment included parenchymal damping $(G)$ and elastance $(H)$. Parenchymal hysteresis [26] values ( $\eta$ ) were calculated as $G / H$. Impedance data points corrupted by the heart rate and its harmonics were omitted from the model fit.
The $Z \mathrm{~L}$ curves obtained in each of the control conditions were ensemble-averaged. The $Z \mathrm{~L}$ data measured after each dose of ET-1 were fitted individually, and the parameter values obtained from the 0.5 -min recording were selected to characterize the constrictor responses.

\section{Statistical analysis}

The parameter values are reported as means \pm SEM. Repeated-measures one-way analysis of variance on ranks with the Student-Newman-Keuls multiple comparison procedure was used to assess the effects of ET-1 on the airway and parenchymal parameters. Statistical significances were accepted at $\mathrm{p}<0.05$.

\section{Results}

Table 1 summarizes the effects of ET-1 on the systemic BP for the guinea-pigs studied. In agreement with previous findings [5-7, 9-11], ET-1 caused marked and statistically significant increases in BP, which were always fully reversible.

The real $(R \mathrm{~L})$ and the imaginary $(X \mathrm{~L})$ parts of a representative baseline $Z \mathrm{~L}$ spectrum, together with the model fit, are shown in figure 1 . The low variations in the $Z \mathrm{~L}$ data indicate the high reproducibility of the measurements: noticeable deviations can be observed only at those frequency points that coincided with the heart rate or its harmonics. Qualitatively, the sharp decrease in $R \mathrm{~L}$ in the low-frequency range is attributed to the viscous resistance of the parenchyma, while the plateau at higher frequencies represents the flow resistance of the airways. The elastic properties of the parenchyma are reflected in the quasi-hyperbolic increase in $X \mathrm{~L}$ in the low-frequency range. The zero crossing and the quasi-linear increase in $X \mathrm{~L}$ at higher frequencies demonstrate the increasing influence of the airway inertance. The model fitted the $Z \mathrm{~L}$ data very well, with no systematic fitting error.

Figure 2 illustrates the set of $Z \mathrm{~L}$ spectra obtained in the control conditions and following the administration of increasing doses of ET-1 in an animal, as real versus imaginary parts (Nyquist plots). The relationships between the $R \mathrm{~L}$ and $X \mathrm{~L}$ are notably linear in the control conditions and during the different levels of ET-1-induced constriction at low frequencies, consistent with the constant-phase behaviour of the parenchyma. Deviations from linearity occur at high frequencies as a result of the dominance of the airway properties: the plateaus in $R \mathrm{~L}$ and the increasing effect of the Iaw on $X \mathrm{~L}$. Increasing

Table 1. - Effects of endothelin-1 on systemic blood pressure (BP)

\begin{tabular}{cc}
\hline $\begin{array}{c}\text { Endothelin-1 dose } \\
\mu \mathrm{g} \cdot \mathrm{kg} \text { of body weight }\end{array}$ & $\begin{array}{c}\text { Change in BP } \\
\%\end{array}$ \\
\hline 0.125 & $14.2 \pm 2.5^{*}$ \\
0.25 & $30.4 \pm 10.5^{*}$ \\
0.5 & $43.3 \pm 16.4^{*}$ \\
1 & $95.9 \pm 15.7^{*}$ \\
2 & $184.4 \pm 14.2^{*}$ \\
\hline
\end{tabular}

$*: \mathrm{p}<0.05$. 

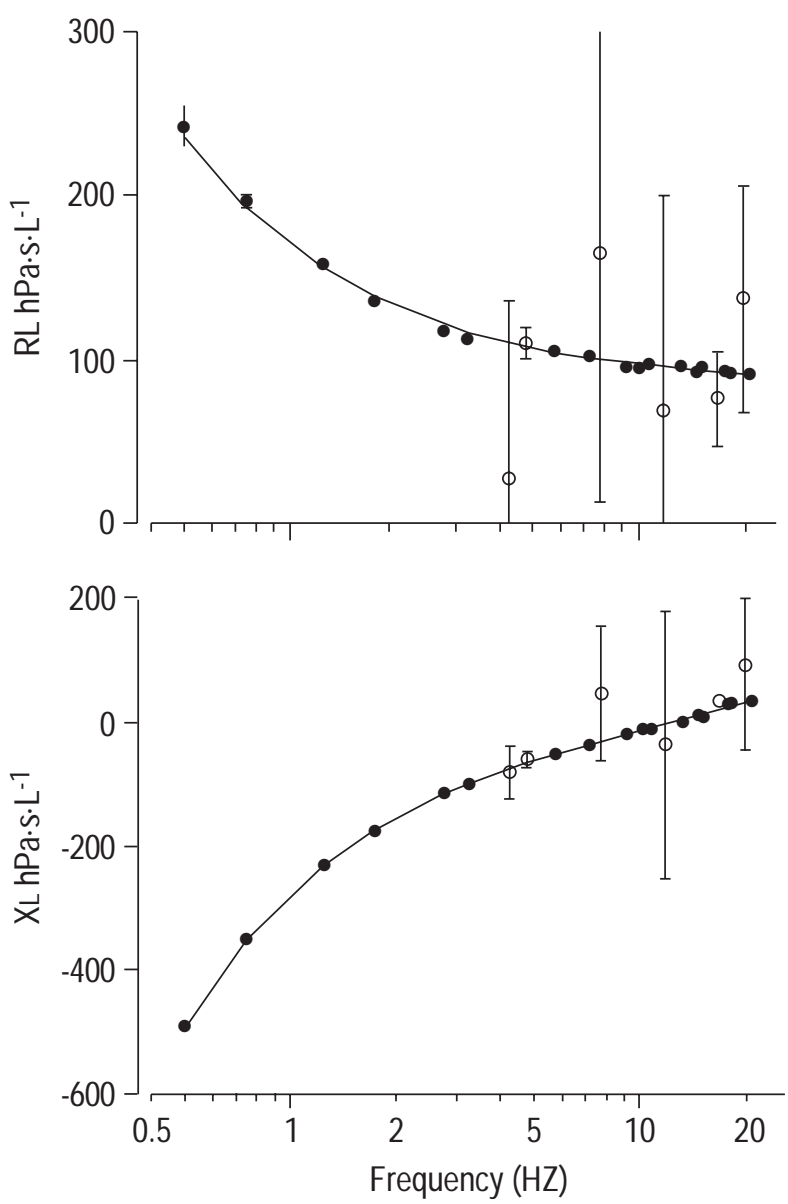

Fig. 1. - Real $(R \mathrm{~L})$ and imaginary $(X \mathrm{~L})$ parts of a representative pulmonary impedance spectrum obtained by averaging five successive measurements in the control condition $(\bullet)$ and the model fit ( - ). Data are mean \pm SEM. $\bigcirc$ : data points corrupted by a cardiac artefact.

doses of ET-1 induced a monotonous increase in the highfrequency $R \mathrm{~L}$, suggesting a marked airway response. However, the increases in $R \mathrm{~L}$ were consistently greater at low-frequencies, indicating dose-dependent increases in the parenchymal resistance. The elevations in the parenchymal elastance are reflected by the increases in the absolute values of the low-frequency $X \mathrm{~L}$. The changing slopes of the $X \mathrm{~L}$ versus $R \mathrm{~L}$ relationships with increasing doses of ET-1 demonstrate a monotonous, dose-dependent increase in the parenchymal $\eta$. The constriction had no influence on the model performance: the differences between the measured and the modelled impedance data were small over the entire frequency range, independently of the lung condition. The baseline $F(1.8 \pm 0.4 \%)$ was not significantly different from those obtained following the administrations of ET- $1(2.2 \pm 0.3 \%, 2.1 \pm 0.3 \%, 2.2 \pm 0.2 \%$, $2.1 \pm 0.2 \%$ and $2.3 \pm 0.4 \%$ for the $0.125,0.25,0.5,1$ and 2 $\mu \mathrm{g} \cdot \mathrm{kg}$ of body weight ${ }^{-1}$ ET-1 bolus, respectively).

Temporal changes in the airway and tissue parameters during successive administrations of ET-1 doses obtained in an experiment are presented in figure 3 . Increasing doses of the constrictor agent induced monotonous elevations in Raw, $G, H$ and $\eta$ at low doses of ET-1, whereas no further increases in $R$ aw and $H$ were observed when the concentration of the ET-1 dose was increased from 1 to $2 \mu \mathrm{g} \cdot \mathrm{kg}$ of body weight ${ }^{-1}$. All of the model parameters returned to

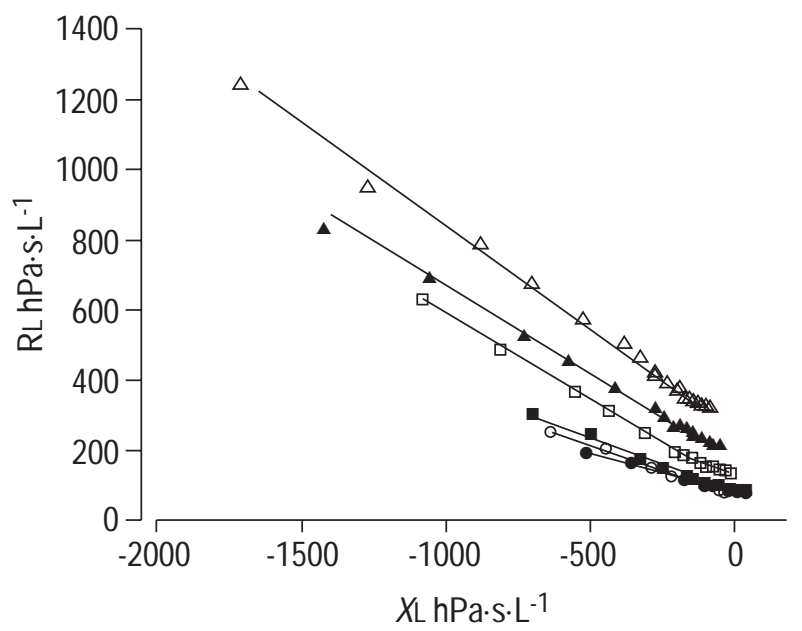

Fig. 2. - Real $(R \mathrm{~L})$ versus imaginary $(X \mathrm{~L})$ parts of pulmonary impedance data obtained in the control condition (C) and following endothelin-1 doses $(\bigcirc: 0.125 ; \mathbf{\square}: 0.25 ; \square: 0.5 ; \boldsymbol{\Delta}: 1 ; \triangle: 2 \mu \mathrm{g} \cdot \mathrm{kg}$ of body weight ${ }^{-1}$ ). For the sake of simplicity, the impedance data points corrupted by a cardiac artefact have been omitted.

baseline following the low doses of ET-1; slight irreversible changes were seen only during severe constrictions. Peak responses occurred $30 \mathrm{~s}$ after administration of ET-1 in all model parameters when the constriction was moderate (following the three or four lowest doses), while the parameter increases were dissociated following the high doses of ET-1. Typically, $G$ and $\eta$ exhibited an instant peak increase after the injection of the bolus, whereas the peak response in $H$ was slightly delayed. Raw occasionally followed the changing pattern of $G$ (e.g. after $1 \mu \mathrm{g} \cdot \mathrm{kg}$ of body weight ${ }^{-1}$ in this example), or displayed a delayed increase (e.g. after $2 \mu \mathrm{g} \cdot \mathrm{kg}$ of body weight $\left.^{-1}\right)$. Despite this asynchrony, the parameter values obtained $30 \mathrm{~s}$ after the ET-1 administrations adequately characterize the lung responses to most of the doses, although this sampling may lead to a slight underestimation of the increases in Raw and $H$ during severe constriction.

Figure 4 summarizes the airway and parenchymal parameters in control conditions and following increasing doses of ET-1 for the total group of animals. Monotonous and statistically significant elevations were obtained at all doses and in all of the parameters but Iaw, the decrease of which became significant only at higher ET-1 doses. Similar elevations occurred in Raw and $G$, with maximal changes of $424 \pm 129 \%$ and $400 \pm 80 \%$ of the baseline values, respectively. The relative increases in $H$ were far smaller, reaching a maximal value of $95 \pm 22 \%$. Since the increases in $G$ systematically exceeded those in $H$, statistically significant increases were obtained in $\eta$, which amounted to $156 \pm 33 \%$ following the highest ET-1 dose. These responses were more or less reversible: no residual effect of ET-1 was observed on Iaw or $\eta$, whereas high doses of ET-1 caused small but statistically significant, lasting increases in Raw $(37 \pm 10 \%), G(32 \pm 7 \%)$ and $H$ $(32 \pm 5 \%)$.

Relative changes in the mechanical parameters to increasing doses of ET-1 are demonstrated in figure 5. The percentage increases for each parameter were calculated by normalizing the responses to the corresponding 

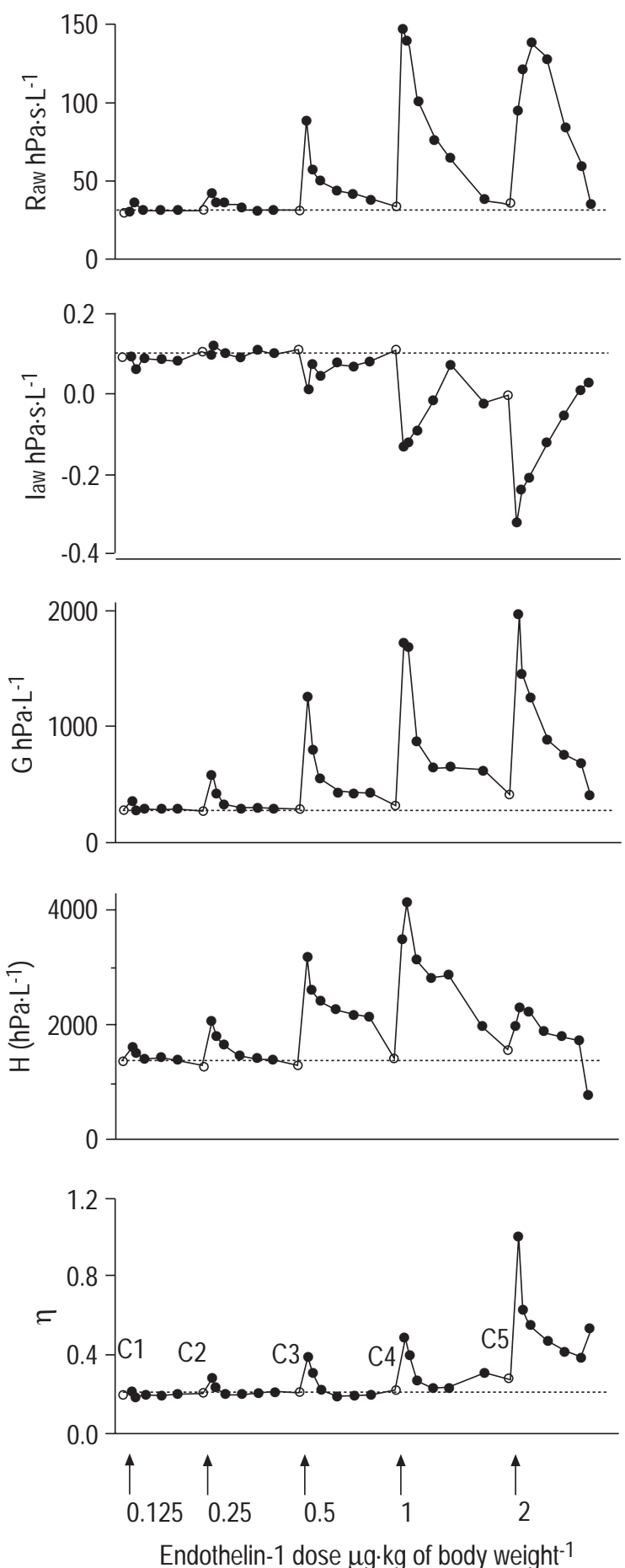

Fig. 3. - Airway and parenchymal parameters in control conditions $(\mathrm{C} 1-\mathrm{C} 5 ; \mathrm{O})$ and their temporal changes during increasing doses of endothelin-1 in a guinea-pig. Raw: airway resistance; Iaw: airway inertance; $G$ : parenchymal damping; $H$ : elastance; $\eta$ : parenchymal hysteresis. - - - : : baseline.

baseline values preceding each ET-1 dose. The marked increases in Raw and $G$ occurred reasonably in parallel, while the elevations in $H$ and $\eta$ were smaller. These increases were statistically significant following each ET1 challenge except that in Raw, which remained at the baseline after the lowest dose of ET-1. No significant changes were found in Iaw after the lower doses of ET-1, whereas the last two doses of ET-1 induced marked and statistically significant decreases.

The ratios WW/DW in the untreated group were significantly lower $(4.7 \pm 0.13)$ than those obtained from the ET-1-challenged guinea-pigs $(5.2 \pm 0.14 ; \mathrm{p}<0.05)$.

\section{Discussion}

The present study demonstrated that the airway responses to ET-1 were associated with significant changes in the mechanical properties of the lung parenchyma. Increasing concentrations of ET-1 induced progressive increases in $R$ aw and monotonous increases in $G$, while $H$ showed a plateau response at the three highest doses. In contrast, Iaw remained at the baseline level when the constrictions were mild, but exhibited significant decreases during severe constrictor responses. Although the changes in all mechanical parameters were fully reversible after the two lowest ET-1 doses, the higher doses caused irreversible parenchymal constrictions, which were associated with statistically significant residual increases in Raw. There were no changes in the baseline levels of Iaw or $\eta$.

To avoid the technical difficulties associated with the flow measurement in a small animal, in the present study the wave-tube technique was adopted to measure ZL. Since this technique proved to afford reliable impedance data in rats [19], and the ZL spectra in the present study are very similar to those obtained in previous studies in this similarsized rodent [19], it was assumed that the ZL curves accurately represent the mechanical impedance of the guinea-pig pulmonary system. Furthermore, in agreement with previous findings in other mammals [15, 17, 21, 23], the model involving an airway and a constant-phase tissue compartment was consistent with the frequency dependence of $Z \mathrm{~L}$ in guinea-pigs, resulting in no systematic fitting errors.

\section{Airway responses}

At low ET-1 doses, the dose-dependent increases in Raw were associated with no significant change in Iaw. For instance, at the ET- 1 dose of $0.25 \mu \mathrm{g} \cdot \mathrm{kg}$ of body weight ${ }^{-1}$ $R$ aw doubled whereas $I$ aw remained at the control level (fig. 5). Since Iaw is thought to be a characteristic parameter of the central airways, this changing pattern suggests a dominance of the periphery in the development of an ET-1 induced airway constriction.

At high ET-1 doses, Raw exhibited further dose-dependent increases, while significant decreases occurred in Iaw, even negative values being attained in most of the animals during severe constriction. This seemingly controversial changing pattern in the airway parameters can be explained as follows. In the present study, the lumped parameters Raw and law were used to characterize the mechanical properties of the overall bronchial tree. While both parameters are proportional to the overall length of the airways, Iaw and Raw are inversely related to the first and second power, respectively, of the overall bronchial cross-sectional area. Therefore, assuming no change in the overall airway length, both $R$ aw and Iaw would be expected to increase with a generalized airway constriction. Although, in theory, Raw can increase while Iaw decreases if 

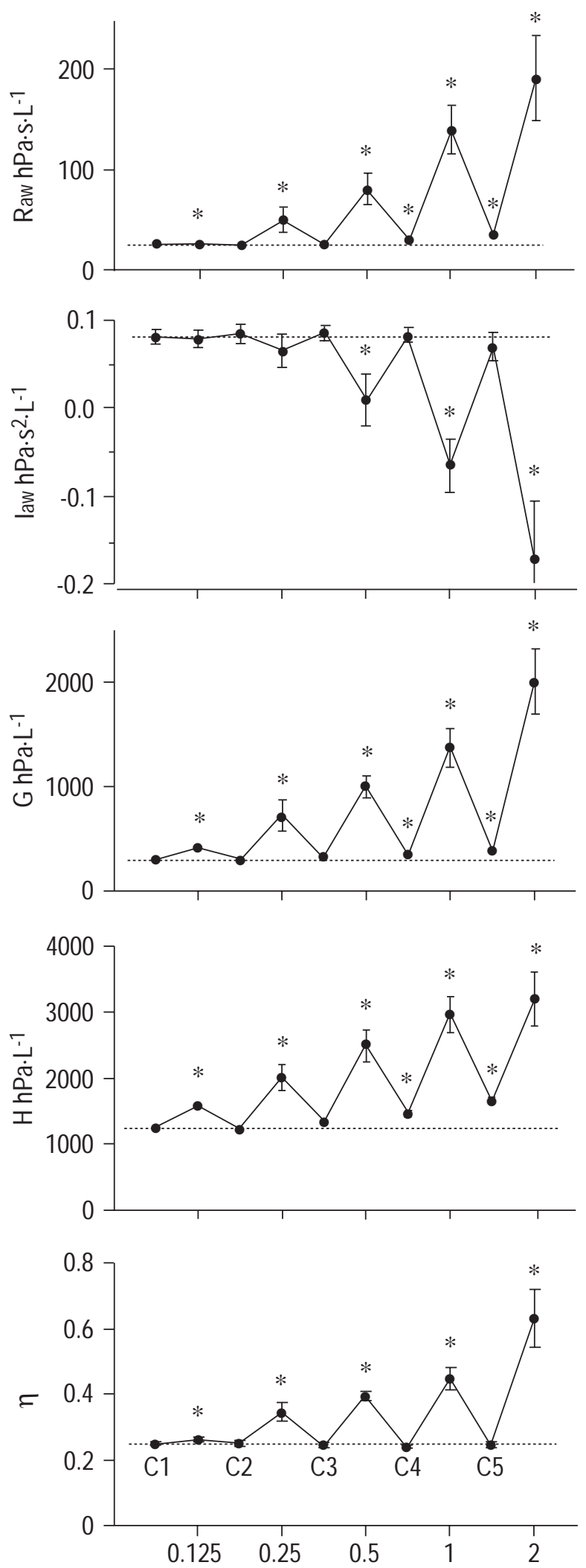

Endothelin-1 dose $\mu \mathrm{g} \cdot \mathrm{kg}$ of body weight ${ }^{-1}$

Fig. 4. - Airway and parenchymal parameters in control condition C1-C5) and their peak responses to endothelin-1 $(0.125-2 \mu \mathrm{g} \cdot \mathrm{kg}$ of body weight ${ }^{-1}$ ) for the overall group of guinea-pigs. $*$ : $p<0.05$ significant difference from the preceding control value. For definition see legend to figure 3. - . - : baseline.

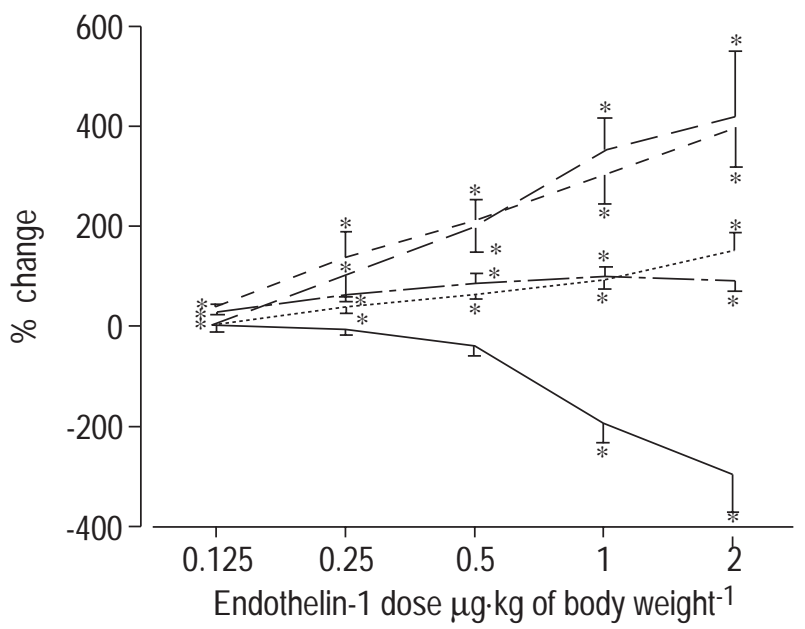

Fig. 5. - The effects of endothelin-1 on the values of the mechanical parameters. The responses in the parameters were normalized to the control values preceding each endothelin-1 dose — _ : airway resistance; $\longrightarrow$ : airway intertance; --- : tissue damping $(G)$; $--\longrightarrow$ : elastance $(H) ; \cdots \cdots: G / H . *$ : $<<0.05$.

the airway constriction is associated with significant airway shortening, the unrealistic negative law parameters obtained at high doses of ET-1 cannot be explained on that basis. Therefore, the opposite changes in Raw and Iaw during constriction can most probably be attributed to the failure of this simple lumped-parameter model during a severe spatial inhomogeneity of the pulmonary constriction. By using a distributed periphery lung model to simulate $Z \mathrm{~L}$ data in control and constricted conditions, HaNTOS et al. [12] demonstrated that, in the presence of an inhomogeneous peripheral constriction, the model-predicted Iaw systematically underestimates the real Iaw. Therefore, the opposite changes in Raw and Iaw at high ET1 doses very probably indicate an inhomogeneous peripheral airway constriction.

\section{Parenchymal responses}

Significant increases in $G$ and $H$ parenchymal parameters during i.v. administrations of ET-1 were obtained. Since the elevations in $G$ exceeded those in $H$, significant increases were obtained in $\eta$ (fig. 5). In parenchymal strips obtained from guinea-pig lungs, FREDBERG et al. [27] demonstrated that different contractile agonists induced greater increases in the tissue resistance than in the elastance. Their data suggested that parenchymal constrictions were always associated with significant increases in the intrinsic $\eta$. Therefore, the constrictor responses in the present study can be interpreted in terms of ET-1 altering the coupling between the resistive and elastic properties at an elementary level of the parenchyma, i.e. ET-1 may induce significant elevations in the intrinsic $\eta$.

The constant-phase tissue model assumes that the entire frequency dependence of $R \mathrm{~L}$ can be attributed to the resistive contribution of the parenchyma, while the quasihyperbolic increase in $X \mathrm{~L}$ reflects lung tissue elasticity. Although this assumption seems to be valid in a relatively homogeneous healthy lung $[15,21]$, inhomogeneous peripheral airway constriction has been shown to increase the frequency dependence of $R \mathrm{~L}[17,19]$. In this condition, 
therefore, the parameter $G$ may contain a significant artefactual component due to inhomogeneous peripheral ventilation [17]. Although the data do not allow an estimation of the roles of the intrinsic and artefactual increases in $G$ separately, the pattern of changes in the mechanical parameters suggests that both phenomena may have been present: the finding that $H$ exhibited marked and statistically significant increases in response to ET-1 suggests real parenchymal constrictions, which were probably associated with significant elevations in the intrinsic $G$, whereas the significant increase in $G$ with no further increase in $H$ at the highest dose of ET-1 can be attributed primarily to the enhanced peripheral inhomogeneity.

\section{Residual effects}

Although perfect returns to baseline were found for each parameter following low doses of ET-1, severe constrictions caused slight, but statistically significant residual elevations in Raw, $G$ and $H$. One possible explanation for such a change would be that the lung remained constricted after the severe ET-1-induced responses. In this case, however, the parameter $\eta$ would also be expected to remain above the baseline level [27]. The slight systematic residual elevations in Raw, $G$ and $H$ can therefore more probably be attributed to slight but irreversible restrictive changes in the lung via a permanent and progressive lung air volume loss. Since hyperinflations were performed between the ET-1 doses to recruit atelectatic alveolar regions, this loss in the lung air volume most probably resulted from pulmonary oedema [28]. The finding in the present study that the ratios WW/DW were significantly higher in guinea-pigs challenged with ET-1 supports this assumption. The possible presence of oedema is in agreement with the results of FILEP et al. [29], who observed increases in the vascular permeability after high doses of ET-1.

\section{Airway and tissue responses to ET-1}

Several authors have demonstrated a significant lung response to an i.v. injection of ET-1 by measuring PIP [7, 9, $10]$ or $R \mathrm{~L}$ and $C$ dyn $[5,6,8,11]$ as indicators of the constriction. However, PIP reflects the overall pressure losses in the lungs, and the value of $R \mathrm{~L}$ contains a flow resistive airway (Raw) and a viscoelastic parenchymal tissue $(R \mathrm{ti})$ component. Accordingly, the methods used in these previous studies do not allow a detailed investigation of the effects of ET-1 on the lung mechanics. NAGASE and coworkers $[16,18]$ separated the ET-1-induced lung responses into airway and parenchymal components in guinea-pigs and in mice. In contrast to the present finding that the relative changes in the airway and parenchymal resistances were approximately equal, they reported an almost 3-times greater elevation in $R \mathrm{ti}(340 \%)$ than that in $R$ aw $(127 \%)$ following a $2.4 \mu \mathrm{g} \cdot \mathrm{kg}$ of body weight ${ }^{-1} i . v$. ET-1 bolus in guinea-pigs. Besides the substantial difference in the size of the guinea-pigs, methodological differences between the studies may explain this discrepancy, as follows. The baseline Raw values obtained by NAGASE et al. [16] were about 4-times greater than those obtained in the present study, suggesting the inclusion of the resistance of the endotracheal tube in their Raw values. This instrumental component of Raw comprises a significant proportion of the total frequency-independent resistance, and this component does not change during constriction. The relative ET-1-induced Raw increases reported by NAGASE et al. [16] may therefore have been underestimations, unlike those in the present study, where the airway responses were based on Raw values excluding the resistance of the tracheal cannula. Moreover, NAGASE et al. [16] separated the airway and parenchymal responses by measuring the local $P \mathrm{~A}$ in open-chest guinea-pigs. It is obvious that the sampling of one or two alveolar regions in a highly inhomogeneously constricted lung [12, 15, 17, 19] makes the capsule-based partitioning highly incidental [21]. Furthermore, in an open-chest guinea-pig (and especially in the mouse [18]), where the outer diameter of the capsule is comparable to the entire sternocostal area of a lobe, the application of a capsule is very likely to influence the airway-tissue separation profoundly, in addition to the overall lung mechanics. The relatively large capsules fix a significant part of the lung surface, and hence may tend to uniformize the $P A$ distribution during constriction. This phenomenon may explain the striking observation by NAGASE et al. [16] that the differences in PA of the two capsules were $<10 \%$, even during severe ET-1-induced constriction. Additionally, it appears that their finding of unusually low baseline $\eta$ values (0.066) with a rather high coefficient of variation $(67 \%)$ can also be attributed to uncertainties related to the $P$ A measurement in a small animal. In the present study, the mechanical properties of the airways and the parenchyma were separated in a far less invasive manner, by evaluating the input impedance data relating to the lungs.

Recent studies on separation of the lung response into airway and parenchymal components have established that constrictor agents, such as methacholine (MCh) [19], histamine [12, 15], prostaglandins [27] and ET-1 [16, 18], act on both the airway and tissue compartments. Although the differences in species and/or methodology may influence the pattern and the magnitude of the lung response, the constrictor agent and its delivery route seem to be the primary determinants of the shares of the airway and tissue compartments in the provoked constriction. For instance, in rats it was demonstrated that the two compartments participated about equally in the $\mathrm{MCh}$-induced constriction when the agent was inhaled, whereas i.v. administered MCh predominantly caused an inhomogeneous airway constriction [19]. The airway responses to $i$.v. administered ET-1 in the present study were associated with significant increases in the parenchymal mechanics which is at odds to the MCh-induced lung responses. This finding suggests that different underlying mechanisms are involved in determining the constrictor responses of the lungs to $\mathrm{MCh}$ and ET-1.

Although it is generally accepted that the parenchyma contributes significantly to the constrictor response of the lungs, the mechanism of the altered lung tissue viscoelasticity is not completely clear. MiTZNER et al. [30] presented experimental evidence that airway contraction could alter the parenchymal mechanics as a consequence of the mechanical interdependence between the airways and the lung tissues. Furthermore, since ET-1 has been shown to constrict the vascular smooth muscle [5-7, 9, 11], lung tissue distortions could also be generated by changes in the vascular smooth muscle tone. Finally, in vitro studies on 
parenchymal strips, where the confounding influence of bronchial or vascular constriction in the tissue response is minimized, suggested that alterations occurred at the parenchymal level, although the increases in the tissue mechanics were much smaller than those observed for the whole lung [27]. The results of the present study do not allow a distinction between the individual effects of these mechanisms. Since ET-1-induced vascular constrictions are not associated with pulmonary vascular engorgement, it is suggested that an altered vasculature per se would not cause such significant (two-fold) increases in the parenchymal parameters. Furthermore, an analysis of the temporal changes in the airway and parenchymal responses to an ET-1 bolus allows an estimation of whether active parenchymal constriction occurred or whether only the indirect effects of the contracting conducting airways are reflected in the elevated $G$ and $H$. The current study indicated distinctly different time courses in the responses of the mechanical parameters following a high dose of i.v. administered ET-1. Typically, in accordance with previous findings [20], the peak responses occurred first in $G$ and $\eta$, while the maximal increases in $R$ aw and $H$ were somewhat delayed. Accordingly, since a number of findings confirm that the airway and parenchymal constrictions in response to other bronchoactive agents are dissociated [13-15], active constriction of the parenchymal contractile elements in response to ET-1 can be suspected, but changes occurring in the lung tissue viscoelasticity as a result of parenchymal distortions might also have been involved when the lung constriction was fully developed.

In summary, it has been demonstrated that increasing doses of endothelin-1 affect the mechanical properties of the airways and the parenchyma in guinea-pigs in a doserelated manner. The dose-response curves for the airway and parenchymal mechanical parameters suggest the dominance of the peripheral airways in the development of the endothelin-1-induced constriction. Although a marked inhomogeneous constriction of the peripheral airways potentially biases an assessment of the changes in the lung tissue mechanics, intrinsic increases clearly occurred in the mechanical properties of the parenchyma. These results indicate that, besides the increases in tone in the vascular and bronchial smooth muscles, endothelin-1 also has a marked constrictor effect on the lung parenchyma.

Acknowledgements. The authors thank I. Kopasz and L.Vígh for excellent technical assistance

\section{References}

1. Yanagisawa M, Kurihara H, Kimura S, et al. A novel potent vasoconstrictor peptide produced by vascular endothelial cells. Nature Lond 1988; 332: 411-415.

2. Durham SK, Goller NL, Lynch JS, Fisher SM, Rose PM. Endothelin receptor B expression in the rat and rabbit lung as determined by in situ hybridization using nonisotopic probes. J Cardiovasc Pharmacol 1993; 22 (Suppl. 8): S1-S3.

3. Markewitz BA, Kohan DE, Michael JR. Endothelin-1 synthesis, receptors, and signal transduction in alveolar epithelium: evidence for an autocrine role. Am J Physiol 1995; 268: L192-L200.

4. Kobayashi Y, Sakamoto Y, Shibasaki M, Kimura I, Matsuo H. Human alveolar macrophages synthesize endothelins by thrombin. J Immunol 1997; 158: 54425447.

5. Macquin-Mavier I, Levame M, Istin N, Harf A. Mechanisms of endothelin-mediated bronchoconstriction in the guinea pig. J Pharmacol Exp Therap 1989; 250: 740745.

6. Schumacher WA, Steinbacher TE, Allen GT, Ogletree ML. Role of thromboxane receptor activation in the bronchospastic response to endothelin. Prostaglandins 1990; 40: 71-79.

7. Pons F, Loquet I, Touvay $\mathrm{C}$, et al. Comparison of the bronchopulmonary and pressor activities of endothelin isoforms ET-1, ET-2, and ET-3 and characterization of their binding sites in guinea pig lung. Am Rev Respir Dis 1991; 143: 294-300.

8. White SR, Darren DP, Tahtaway P, et al. Epithelial modulation of airway smooth muscle response to endothelin-1. Am Rev Respir Dis 1991; 144: 373-378.

9. Lueddeckens G, Bigl H, Sperling J, Becker K, Braquet P, Förster W. Importance of secondary $\mathrm{TXA}_{2}$, release in mediating of endothelin-1 induced bronchoconstriction and vasopressin in the guinea-pig. Prostagland Leuk Essent Fatty 1993; 48: 261-263.

10. Noguchi K, Noguchi $\mathrm{Y}$, Hirose $\mathrm{H}$, et al. Role of endothelin $\mathrm{ET}_{\mathrm{B}}$ receptors in bronchoconstrictor and vasoconstrictor responses in guinea-pigs. Eur J Pharmacol 1993; 233: 47-51.

11. Polakowski JS, Opgenorth TJ, Pollock DM. ET $\mathrm{A}_{\mathrm{A}}$ receptor blockade potentiates the bronchoconstrictor response to ET-1 in the guinea pig airway. Biochem Biophys Res Comn 1996; 225: 225-231.

12. Hantos Z, Daróczy B, Suki B, Nagy S, Fredberg JJ. Input impedance and peripheral inhomogeneity of dog lungs. $J$ Appl Physiol 1992; 72: 168-178.

13. Bates JHT, Lauzon A-M, Dechman GS, Maksym GN, Schuessler TF. Temporal dynamics of pulmonary response to intravenous histamine in dogs: effect of dose and lung volume. J Appl Physiol 1994; 76: 616-626.

14. Lutchen KR, Suki B, Zhang Q, Peták F, Daróczy B, Hantos Z. Airway and tissue mechanics during physiological breathing and bronchoconstriction in dogs. $J$ Appl Physiol 1994; 77: 373-385.

15. Hantos Z, Peták F, Adamicza Á, Daróczy B, Fredberg JJ. Differential responses of global airway, terminal airway, and tissue impedances to histamine. J Appl Physiol 1995; 79: $1440-1448$.

16. Nagase T, Fukuchi Y, Matsui H, Aoki T, Matsuse T, Orimo H. In vivo effects of endothelin A- and B-receptor antagonists in guinea pigs. Am J Physiol 1995; 268: L846-L850.

17. Lutchen KR, Hantos Z, Peták F, Adamicza Á, Suki B. Airway inhomogeneities contribute to apparent lung tissue mechanics during constriction. J Appl Physiol 1996; 80: $1841-1849$.

18. Nagase T, Matsui H, Aoki T, Ouchi Y, Fukuchi Y. Lung tissue behavior in the mouse during constriction induced by methacholine and endothelin-1. J Appl Physiol 1996; 81: 2373-2378.

19. Peták F, Hantos Z, Adamicza Á, Asztalos T, Sly PD. Methacholine-induced bronchoconstriction in rats: effects of intravenous vs. aerosol delivery. J Appl Physiol 1997; 82: 1479-1487.

20. Suki B, Peták F, Adamicza Á, Daróczy B, Lutchen KR, 
Hantos Z. Airway and tissue constrictions are greater in closed than in open-chest conditions. Respir Physiol 1997; 108: 129-141.

21. Peták F, Hantos Z, Adamicza Á, Daróczy B. Partitioning of pulmonary impedance: modeling vs. alveolar capsule approach. J Appl Physiol 1993; 75: 513-521.

22. Hantos Z, Adamicza Á, Govaerts E, Daróczy B. Mechanical impedance of the lungs and chest wall in the cat. $J$ Appl Physiol 1992; 73: 427-433.

23. Suki B, Peták F, Adamicza Á, Hantos Z, Lutchen KR. Partitioning of airway and lung tissue properties: comparison of in situ and open-chest conditions. J Appl Physiol 1995; 79: 861-869.

24. Van de Woestijne KP, Franken H, Cauberghs M, Làndssr FJ, Clément J. A modification of the forced oscillation technique. In: Hutás I, Debreczeni LA, eds. Advances in Physiological Sciences. Respiration. Proceedings of the 28th International Congress of Physiological Sciences. Vol. 10. Oxford, Pergamon, 1981; pp. 655-660.
25. Franken H, Clément J, Cauberghs M, Van de Woestijne KP. Oscillating flow of a viscous compressible fluid through a rigid tube: a theoretical model. IEEE Trans Biomed Eng 1981; 28: 416-420.

26. Fredberg JJ, Stamenovic D. On the imperfect elasticity of lung tissue. J Appl Physiol 1989; 67: 2408-2419.

27. Fredberg JJ, Bunk D, Ingenito E, Shore SA. Tissue resistance and the contractile state of lung parenchyma. $J$ Appl Physiol 1993; 74: 1387-1397.

28. Grossman RF, Jones JG, Murray JF. Effects of oleic acidinduced pulmonary edema on lung mechanics. $J$ Appl Physiol 1980; 48: 1048-1051.

29. Filep JG, Fournier A, Földes-Filep E. Acute pro-inflammatory actions of endothelin-1 in the guinea-pig lung: involvement of $\mathrm{ET}_{\mathrm{A}}$ and $\mathrm{ET}_{\mathrm{B}}$ receptors. Br J Pharmacol 1995; 115: 227-236.

30. Mitzner W, Blosser S, Yager D, Wagner E. Effect of bronchial smooth muscle contraction on lung compliance. J Appl Physiol 1992; 72: 158-167. 